\title{
Tracing the effect of the melanocortin-4 receptor pathway in obesity: study design and methodology of the TEMPO registry
}

This article was published in the following Dove Press journal: The Application of Clinical Genetics

\author{
Ihuoma Eneli ${ }^{1,2}$ \\ Jinyu $\mathrm{Xu}{ }^{\prime}$ \\ Matthew Webster ${ }^{3}$ \\ Amy McCagg ${ }^{3}$ \\ Lex Van Der Ploeg ${ }^{3}$ \\ Alastair S Garfield ${ }^{3}$ \\ Elizabeth Estrada ${ }^{4}$ \\ 'Center for Healthy Weight and \\ Nutrition, Nationwide Children's \\ Hospital, Columbus, OH, USA; \\ ${ }^{2}$ Department of Pediatrics, The Ohio \\ State University, Columbus, OH, USA; \\ ${ }^{3}$ Department of Medical \\ Communications, Rhythm \\ Pharmaceuticals, Inc, Boston, MA, USA; \\ ${ }^{4}$ Department of Pediatric Endocrinology, \\ University of North Carolina, Chapel Hill, \\ NC, USA
}

Correspondence: Ihuoma Eneli

Center for Healthy Weight and Nutrition,

700 Children's Drive, LA 5F, Columbus,

$\mathrm{OH} 43205$, USA

Tel + | 614 722 48I|

$\mathrm{Fax}+$ I 614 7223099

Email Ihuoma.Eneli@nationwidechildrens.org
Purpose: The hypothalamic melanocortin-4 receptor (MC4R) pathway, a component of the central melanocortin pathway, regulates energy balance and satiety. Rare genetic disorders of obesity may be characterized by impaired MC4R pathway signaling, which results in earlyonset severe obesity and insatiable hunger (hyperphagia). The TEMPO registry (NCT03479437) is a voluntary, prospective, open-ended registry of individuals with rare genetic disorders of obesity due to mutations in genes within the MC4R pathway who have early-onset severe obesity. The objective of the TEMPO registry is to evaluate the burden of rare genetic disorders of obesity on individuals, their parents/caregivers, health care providers, and the health care system.

Patients and methods: Individuals with rare genetic disorders of obesity (adults aged $\geq 18$ years and children and adolescents aged from 2 to 17 years) will be referred by their health care providers or by a genetic screening study. Individuals must meet age- and sex-specific body mass index values that define the clinical criteria for severe obesity and carry selected variants in $M C 4 R$ or in one of several genes upstream or downstream of the MC4R. Online surveys will be completed by the individual, parent/caregiver, and health care provider at baseline and annually thereafter and will collect data on demographics, results of genetic testing, medical/family history, disease characteristics, resource utilization, eating habits/ hunger episodes, social and emotional impacts, and interest in future clinical trial participation.

Conclusions: The TEMPO registry will provide insights into the overall course and disease burden for individuals with rare genetic disorders of obesity. Health care providers may use this resource to improve the identification, diagnosis, and treatment of individuals with rare forms of genetic obesity.

Keywords: Alström syndrome, Bardet-Biedl syndrome, LEPR, PCSK1, POMC, severe obesity

\section{Plain language summary}

Obesity is a complex disorder caused, to a large extent, by genetic factors. Some individuals with severe obesity represent a distinct and rare genetic subgroup. These rare genetic disorders of obesity are characterized by genetic mutations that control appetite and energy balance, which can cause the individual to feel insatiable hunger, leading to severe obesity at a very early age. Rare genetic disorders of obesity are underdiagnosed, poorly understood, and negatively impact quality of life, mental health, and life span. The TEMPO registry will collect information from individuals, caregivers, and healthcare providers to study how rare genetic disorders of obesity affect individuals, their families, and their communities. 
Healthcare providers will also be able to use the TEMPO registry as an educational resource when treating individuals with rare genetic disorders of obesity.

\section{Introduction}

Obesity is a multifactorial, chronic disease with diverse etiologies. ${ }^{1,2}$ Although obesity can be influenced by environmental factors, genetic contributions play crucial roles in obesity. In children, genetic factors contribute to over $80 \%$ of body mass index (BMI) variations. ${ }^{3}$ A subset of genetic factors serve a pronounced role in rare genetic disorders of obesity, and selected genetic variants are responsible for $5-10 \%$ of early-onset obesity. ${ }^{3}$

Body weight is determined by the balance between food intake and energy expenditure. ${ }^{4}$ The hypothalamus regulates both aspects in response to cues from peripheral hormones (such as leptin [LEP] or ghrelin) that reflect the nutritional state. Within the hypothalamus, the melanocortin-4 receptor (MC4R) pathway, which is a component of the central melanocortin pathway, regulates satiety and energy utilization (Figure 1). ${ }^{2,5-7}$ This pathway comprises key proteins upstream of the MC4R, such as LEP, LEP receptor (LEPR), pro-opiomelanocortin (POMC), and proprotein convertase subtilisin/kexin type 1 (PCSK1). ${ }^{2}$ This pathway also includes protein complexes involved in
Bardet-Biedl syndrome (BBS 1-20) and Alström syndrome 1 (ALMS1), which support the functional status of receptors such as LEPR at the cell surface. ${ }^{8,9}$ Briefly, LEP binds to LEPR located on the surface of POMC neurons in the arcuate nucleus of the hypothalamus. ${ }^{10}$ This triggers a signaling cascade in which the POMC precursor polypeptide is processed by enzymes, including PCSK1, into neuropeptides, which include $\alpha$ - and $\beta$-melanocyte-stimulating hormone. These neuropeptides can activate MC4R to promote satiety, energy expenditure, and weight loss. Countering this effect is the MC4R antagonist agoutirelated protein, which leads to increased food consumption, decreased energy expenditure, and weight gain. ${ }^{11}$ Activation of the MC4R results in further downstream signaling, including the production of brain-derived neurotrophic factor and transcription factor single-minded 1, which mediate the effects of the MC4R by helping to reduce food intake and/or modulate energy expenditure. ${ }^{12}$

To date, rare genetic disorders of obesity characterized by impaired MC4R pathway signaling include $M C 4 R$, $P O M C, P C S K 1, L E P$, and $L E P R$ biallelic deficiencies, as well as BBS and Alström syndrome. ${ }^{2,13-15}$ These rare genetic disorders often result in early-onset severe obesity and insatiable hunger (termed hyperphagia), in addition to other clinical presentations. The most common form of

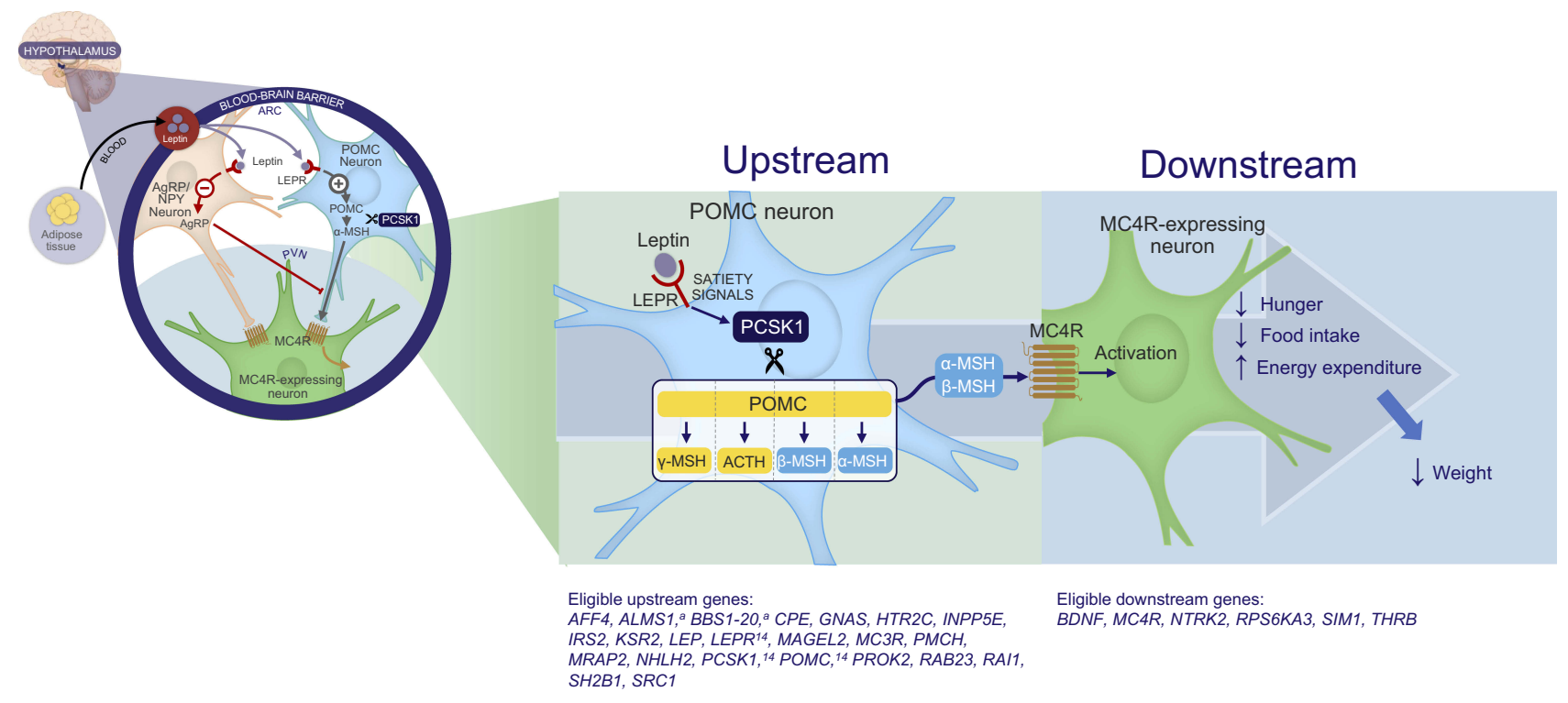

Figure I The MC4R signaling pathway plays a vital role in regulating appetite and energy balance. Briefly, LEP binds to LEPR on POMC neurons in the arcuate nucleus of the hypothalamus. This triggers a signaling cascade in which the POMC precursor polypeptide is processed by enzymes, including PCSKI, into neuropeptides, which include $\alpha$ and $\beta-\mathrm{MSH}$. These neuropeptides can activate MC4R to promote satiety, energy expenditure, and weight loss. Mutations in this pathway can result in rare genetic disorders of obesity. Individuals enrolled in the TEMPO registry must have homozygous, compound heterozygous, heterozygous, or composite heterozygous mutations in one of several genes upstream or downstream of $M C 4 R$. ${ }^{a}$ Only if there is no evidence of clinical syndromic features, likely heterozygous individuals only.

Abbreviations: AgRP, agouti-related protein; ARC, arcuate nucleus; LEP, leptin; LEPR, leptin receptor; MC4R, melanocortin-4 receptor; MSH, melanocyte-stimulating hormone; NPY, neuropeptide Y; PCSKI, pro-protein convertase subtilisin/kexin type I; POMC, proopiomelanocortin; PVN, paraventricular nucleus. 
monogenetic obesity is $M C 4 R$ deficiency, which is reported in up to $6 \%$ in individuals with obesity. ${ }^{4,16}$ Individuals with $M C 4 R$ deficiency can present with an early history of hyperphagia, as well as hyperinsulinemia, accelerated growth, advanced bone age, and lack of dysmorphology. ${ }^{16}$ Individuals with $P O M C, L E P$, or $L E P R$ deficiencies may also experience endocrine abnormalities, including hypothyroidism, hypogonadism, and adrenal insufficiency. ${ }^{2,13}$ PCSK1 biallelic deficiency can be characterized by early-life failure to thrive and malabsorptive diarrhea, which later in childhood evolves into severe obesity and hyperphagia. ${ }^{2,17,18} \mathrm{BBS}$ is characterized by hypogonadism, visual impairment, cognitive impairment, and renal dysfunction, whereas Alström syndrome is characterized by retinal dystrophy, deafness, and diabetes. $^{13}$

For individuals with rare genetic disorders of obesity, the severity of obesity can depend on the individual's zygosity. For instance, individuals with rare homozygous or compound heterozygous mutations in the $M C 4 R$ gene present with more severe obesity compared with individuals with heterozygous $M C 4 R$ mutations. ${ }^{19}$ In a study of individuals with $M C 4 R$ deficiency, all homozygotes had severe obesity compared with $68 \%$ of heterozygotes. These findings suggest that the degree of obesity in heterozygous carriers can depend on the degree of functional MC4R expression. ${ }^{19}$ In support, heterozygous mutation carriers often present with variable expression or incomplete penetrance, resulting in diverse severity and onset of obesity even among related individuals. $^{20,21}$ Further, the in vitro function of $M C 4 R$ is correlated with phenotype, given that individuals with a complete loss-of-function mutation in $M C 4 R$ were taller and had greater bone mineral density, energy intake, and plasma insulin compared with individuals who had a partial loss-of-function mutation in $M C 4 R{ }^{19}$

Biallelic deficiencies in LEPR, POMC, or PCSK1 are predicted to affect an estimated 12,800 individuals in the United States. ${ }^{14}$ However, this conservative estimate does not include individuals with heterozygous or composite heterozygous variants; composites have a loss-of-function defect in 2 or more alleles from among 2 or more of the 3 (POMC, PCSK1, and LEPR) MC4R pathway genes. It is likely that most of these MC4R pathway deficiencies remain undiagnosed, as genetic testing in individuals with obesity is often lacking as a routine medical practice. The prevalence of 2 other MC4R pathway-associated genetic disorders, BBS and Alström syndrome, is also low. ${ }^{13}$ The prevalence of BBS ranges from 1 in 125,000 to 1 in 175,000 births, and Alström syndrome has been diagnosed in about 950 individuals worldwide. $^{13}$ Screening to detect MC4R pathway deficiencies can help identify individuals with these rare disorders.

Early diagnosis and treatment strategies can improve quality of life, particularly for young individuals. In children with $M C 4 R$ deficiency, rates of type 2 diabetes may be attributed to rapid weight gain. ${ }^{22}$ Hyperphagia and foodrelated distress have also been reported in children 6-8 months of age with $M C 4 R$ deficiency. ${ }^{16}$ Although BMI gain stabilizes and hyperphagia lessens with age in individuals with $M C 4 R$ deficiency, severe obesity in adults negatively affects both physical and mental health. ${ }^{19,22,23}$ Other MC4R pathway variants may present unique diagnostic challenges. For example, rates of BMI gain are greater in children with $L E P$ or $L E P R$ deficiency compared with those with $M C 4 R$ deficiency. ${ }^{24}$ Diagnosis and proper treatment are crucial to improving the quality of life and may also reduce social stigma or feelings of guilt or blame experienced by individuals with rare genetic disorders of obesity and their parents/caregivers. ${ }^{25}$ The TEMPO registry is a voluntary, ongoing, open-ended international registry that enrolls individuals with impaired MC4R pathway signaling due to rare mutations resulting in early-onset severe obesity. The registry captures data provided by the individual, parent/caregiver, and health care provider using electronic surveys administered at baseline and annually thereafter. The TEMPO registry will evaluate the burden of rare genetic disorders of obesity on individuals, parents/caregivers, health care providers, and the health care system to provide insight into the overall disease course. Health care providers may use the TEMPO registry to improve the identification, diagnosis, and treatment of rare genetic disorders of obesity. ${ }^{26}$

\section{Materials and methods}

\section{Eligibility}

\section{Inclusion criteria}

To be eligible for inclusion in the TEMPO registry, individuals with rare genetic disorders of obesity must meet age- and sex-specific BMI values for the clinical criteria for severe obesity (Figure 2, Supplementary Data). The registry includes individuals aged $\geq 2$ years with rare genetic disorders of obesity. In adults ( $\geq 18$ years of age), severe obesity is defined as BMI $>40 \mathrm{~kg} / \mathrm{m}^{2}$. In children aged 2-17 years, severe obesity is defined as BMI $>1.4$ times that of the age- and sex-adjusted 95th percentile value. In addition, adults, adolescents, and children must 
Inclusion criteria

Adults: $\mathrm{BMI}>40 \mathrm{~kg} / \mathrm{m}^{2}$

Child: $\mathrm{BMI}>1.4 \times$ 95 th percentile value

Homozygous, compound heterozygous, heterozygous, or composite heterozygous mutations in the MC4R pathway

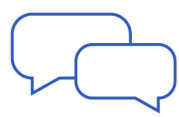

Referral

Individuals who meet inclusion criteria are referred to the registry by healthcare providers (HCPs) or genetic screening studies

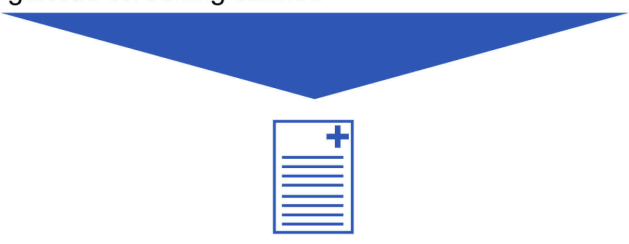

Enrollment

Participants, caregivers/parents, and HCPs are enrolled in the registry

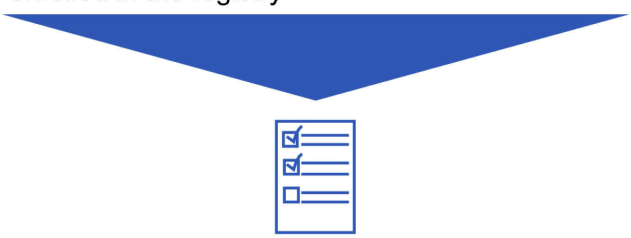

Baseline survey

Participants, caregivers, and HCPs fill out respective baseline surveys

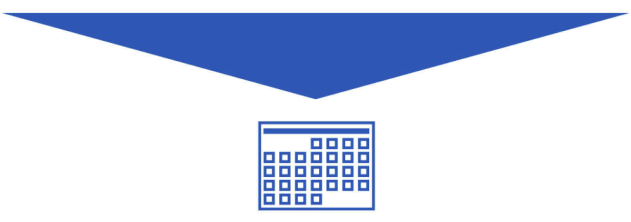

Follow-up surveys

Participants, caregivers, and HCPs are contacted annually to complete follow-up surveys

Figure 2 TEMPO registry study design.

have homozygous, compound heterozygous, heterozygous, or composite heterozygous mutations in genes of the MC4R pathway, which include the $M C 4 R$ gene and selected variants in one of several genes upstream or downstream of $M C 4 R$ (Table 1).

\section{Exclusion criteria}

Individuals diagnosed with syndromic forms of obesity such as BBS, Alström syndrome, or Prader-Willi syndrome will be excluded. These individuals will be referred to their disease-specific registries where available.
Table I Genes associated with the MC4R pathway for which individuals are screened to determine eligibility for the TEMPO registry

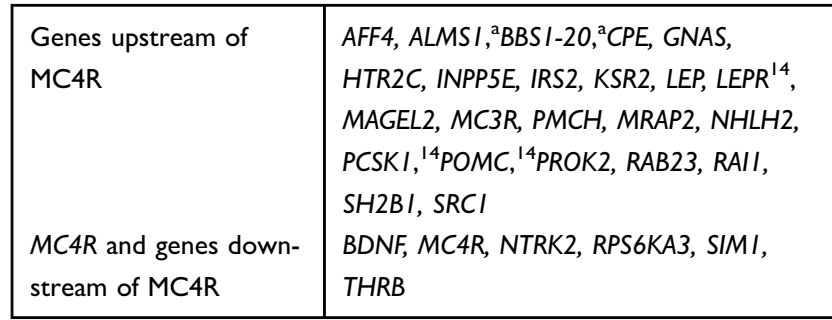

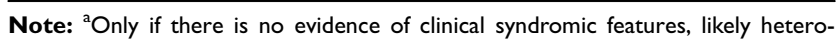
zygous individuals only.

\section{Referral}

Individuals who meet the genetic and phenotypic criteria for the TEMPO registry are referred to coordinating centers by their health care providers or by industry-sponsored genetic screening studies. Physicians who are known to have patients with rare genetic disorders of obesity are provided information about the registry and asked to refer patients and parents/ caregivers to coordinating centers.

More than 1 patient from the same household can be referred to and enrolled in the TEMPO registry. Each patient will receive a unique user identification and be linked through the TEMPO platform to the referring physician and caregiver (if applicable). Patients within the same household will not be linked through the system, but the referring physician will indicate in their survey if the patient has other biological family members who have a genetic variant linked to obesity.

\section{Enrollment}

The coordinating center screens and enrolls participants in the registry. All adult individuals with rare genetic disorders of obesity and parents/caregivers of pediatric or adolescent individuals complete a consent form, and minors aged 1317 years complete an assent form. Individuals enrolled in the study are included indefinitely unless or until they withdraw consent; however, the enrollment period of new individuals will last 5 years. Currently, the TEMPO registry is open to enrollment in the United States. The registry has been submitted for ethics review in Canada, and European TEMPO coordinating centers are being selected.

Eligible individuals, parents/caregivers, and health care providers are included in the registry only after providing consent/assent per regulation in the individual's country of residence. Affected individuals and their parents/caregivers have the right to withdraw from the registry at 
any time for any reason, without prejudice to their medical care. All communications, reports, and data on individuals will be identified only by a coded number to maintain confidentiality.

All local regulations and ethics requirements are followed for each country in which individuals are enrolled. The TEMPO registry is approved by a hospital institutional review board/ethics committee (Nationwide Children's Hospital, Columbus, OH; Karen A. White, $\mathrm{PhD}$, Chair) and complies with the International Conference on Harmonisation, Harmonised Tripartite Guideline Pharmacovigilance Planning, the Declaration of Helsinki, and other applicable regulatory requirements.

\section{Online surveys Baseline}

Following enrollment, health care providers complete an online survey reporting baseline demographics (including age, race, sex, and location of diagnosis) and disease characteristics in the affected individual. Affected individuals and parents/caregivers complete their respective baseline surveys on the burden of disease. The parent/ caregiver completes the survey on behalf of individuals aged $\leq 17$ years, though adolescent individuals aged 13-17 years may assist in completing the survey. The parent/ caregiver may assist adult individuals depending on their need for support or subject matter understanding.

The health care provider baseline survey collects the following information: demographics (including age, race, and sex), genetic testing identifying genes of interest, symptoms and comorbidities present, medical history (eg, height, weight, age at which obesity was identified, hair color, gastrointestinal complications in early life, failure to thrive in infancy, comorbidities, medical treatment history, current medication, surgeries, developmental delays), and relevant pedigree of obesity history for family members (if available).

The parent/caregiver baseline survey collects information about parent/caregiver demographics, as well as the patient's food and hunger episodes, physical activity, quality of life (eg, bullying, limitations on activities, health concerns), and impact on the family. The patient baseline survey collects similar information as the parent/caregiver survey, with the addition of questions on education, development, and employment.

\section{Annual follow-ups}

Enrolled individuals, parents/caregivers, and health care providers are contacted annually by the coordinating center to complete an online follow-up survey, which includes a smaller subset of questions from the baseline survey. The period of follow-up is open-ended.

\section{Survey validation and data management}

The surveys used in the TEMPO registry were developed by an advisory board of treating physicians, survey developers, and child psychologists. The surveys include aspects of validated questionnaires such as the Impact of Weight on Quality of Life-Kids and Pediatric Quality of Life Inventory Family Impact Module, as well as questions developed by the advisory board to specifically address the needs, eating characteristics, and burden of individuals with rare genetic disorders of obesity. The surveys were tested with referring physicians, adults, and young adults with severe obesity and hunger, and caregivers of pediatric individuals to ensure understanding of the survey tool and ease of use with the electronic platform.

Coordinating centers have been selected to manage TEMPO registry enrollment, data entry, and patient follow-up. The coordinating center will follow up directly with registry participants on missing or late data as allowable by local ethics committees and laws. The coordinating center will make 3 attempts to contact the patient to complete the surveys annually.

Information in the TEMPO registry will not be directly used in clinical trials. Further, data within the registry are currently limited to participating country coordinating centers and Rhythm Pharmaceuticals, Inc. At this time, the information will not be accessible to individuals without an affiliation to Rhythm Pharmaceuticals, Inc., or TEMPO. Requests for data from participating investigators will be reviewed by the coordinating center and Rhythm Pharmaceuticals, Inc., which will determine whether deidentified data can be shared. If agreed, data would be provided through a secure download of the requested deidentified data.

\section{Discussion}

The TEMPO registry offers a standardized protocol for collecting data from a variety of participants who may be affected by rare genetic disorders of obesity. Information gathered through the TEMPO registry can help evaluate the burden of rare genetic disorders of obesity on affected individuals, parents/caregivers, health care providers, and the health care system. Because it captures information about nearly 50 candidate genes surrounding the MC4R pathway, the registry serves as a comprehensive data repository for researchers studying rare genetic disorders of obesity. Like other disease state registries, the TEMPO registry may provide data for 
analyses that can help improve the diagnosis and treatment of individuals with rare genetic disorders of obesity. For instance, a recent analysis of a national specialist clinic in the United Kingdom and an international registry of individuals with Alström syndrome reported that renal disease has an early onset and progresses rapidly to chronic kidney disease in these individuals, a finding that will have a substantial impact on screening and treatment for renal disease in individuals with Alström syndrome. ${ }^{27}$ Similarly, the TEMPO registry may provide comparable insights into the treatment of rare genetic disorders of obesity, including POMC, LEP, LEPR, PCSK1, and $M C 4 R$ deficiencies.

The TEMPO registry has several limitations. First, individuals must be referred by a health care provider or by a genetic screening study. Rare genetic disorders of obesity are often underdiagnosed, and as such, health care providers may not be aware of the need to recommend genetic screening. To address this limitation, it is crucial to educate health care providers on the clinical characteristics of rare genetic disorders of obesity and to encourage them to recommend individuals with severe early-onset obesity for genetic screening. Another anticipated challenge is adherence to annual follow-up surveys. Because this is a volunteer registry, completion of the surveys will depend on participants' engagement. Thus, the usability of the TEMPO registry online platform has been configured to be intuitive and easy to complete, with a readability level between fifth and eighth grade to enhance participation and completion of the surveys. In addition, the health care providers can encourage participants' adherence during regular checkups. Use of online surveys will also encourage greater response rates, as participants do not have to report to a coordinating center to complete a survey.

The TEMPO registry captures demographics and disease characteristics from individuals with rare genetic disorders of obesity, their parents/caregivers, and their health care providers. Using this information, the registry evaluates the impact of rare genetic disorders of obesity on these participants and the healthcare system overall. The TEMPO registry is a noninterventional study as it does not offer treatment options for affected individuals. What is most promising is that the registry will provide the largest repository of data from individuals with these rare genetic disorders of obesity followed over a period of time. Thus, the TEMPO registry will provide information that can help health care providers and researchers improve the identification of individuals with rare genetic disorders of obesity, better understand the natural history of the disorder, and investigate potential interventions.

\section{Acknowledgments}

This study was sponsored by Rhythm Pharmaceuticals, Inc. Assistance with preparation of this manuscript was provided by MedThink SciCom by Deirdre Rodeberg, $\mathrm{PhD}$, and David Boffa, ELS, and was funded by Rhythm Pharmaceuticals, Inc. The abstract of this article was presented at the 2018 European Society for Paediatric Endocrinology Annual Meeting as a poster presentation with interim findings. The poster's abstract was published in "Poster Presentations" in Hormone Research in Paediatrics: https://www.karger.com/Article/Pdf/492307.

\section{Author contributions}

All authors contributed to data analysis, drafting and revising the article, gave final approval of the version to be published, and agree to be accountable for all aspects of the work.

\section{Disclosure}

Lex Van Der Ploeg, Alastair S Garfield, Matthew Webster, and Amy McCagg are employees of Rhythm Pharmaceuticals, Inc. Elizabeth Estrada is a consultant for and reports personal fees from Rhythm Pharmaceuticals, Inc. Jinyu Xu is a research coordinator for the TEMPO registry and reports grants from Rhythm Pharmaceuticals Inc. Ihuoma Eneli has received funding from Rhythm Pharmaceuticals, Inc. Ihuoma Eneli also reports grants from National Institute for Health, PCORI, Rhythm Pharmaceuticals, Nestle, and also received a contract for consulting for the American Academy of Pediatrics, during the conduct of the study. Lex Van Der Ploeg has a patent Rhythm IP licensed. The authors report no other conflicts of interest in this work.

\section{References}

1. Dayton K, Miller J. Finding treatable genetic obesity: strategies for success. Curr Opin Pediatr. 2018;30(4):526-531. doi:10.1097/ MOP.0000000000000641

2. Da Fonseca ACP, Mastronardi C, Johar A, Arcos-Burgos M, PazFilho G. Genetics of non-syndromic childhood obesity and the use of high-throughput DNA sequencing technologies. J Diabetes Complications. 2017;31(10):1549-1561. doi:10.1016/j. jdiacomp.2017.04.026

3. Heymsfield SB, Avena NM, Baier L, et al. Hyperphagia: current concepts and future directions proceedings of the 2 nd international conference on hyperphagia. Obesity (Silver Spring). 2014;22(Suppl 1): S1-S17. doi:10.1002/oby.20646 
4. Bell CG, Walley AJ, Froguel P. The genetics of human obesity. Nat Rev Genet. 2005;6(3):221-234. doi:10.1038/nrg1556

5. Shen WJ, Yao T, Kong X, Williams KW, Liu T. Melanocortin neurons: multiple routes to regulation of metabolism. Biochim Biophys Acta Mol Basis Dis. 2017;1863(10 Pt A):2477-2485. doi:10.1016/j.bbadis.2017.05.007

6. Kuhnen P, Krude H, Biebermann H. Melanocortin-4 receptor signalling: importance for weight regulation and obesity treatment. Trends Mol Med. 2019;25(2):136-148. doi:10.1016/j.molmed.2018.12.002

7. Goncalves JPL, Palmer D, Meldal M. MC4R agonists: structural overview on antiobesity therapeutics. Trends Pharmacol Sci. 2018;39(4):402-423. doi:10.1016/j.tips.2018.01.004

8. Seo S, Guo DF, Bugge K, Morgan DA, Rahmouni K, Sheffield VC. Requirement of Bardet-Biedl syndrome proteins for leptin receptor signaling. Hum Mol Genet. 2009;18(7):1323-1331. doi:10.1093/hmg/ ddp031

9. Girard D, Petrovsky N. Alström syndrome: insights into the pathogenesis of metabolic disorders. Nat Rev Endocrinol. 2011;7(2):7788. doi:10.1038/nrendo.2010.210

10. Yazdi FT, Clee SM, Meyre D. Obesity genetics in mouse and human: back and forth, and back again. PeerJ. 2015;3:e856.

11. Krashes MJ, Lowell BB, Garfield AS. Melanocortin-4 receptor-regulated energy homeostasis. Nat Neurosci. 2016;19(2):206-219. doi: $10.1038 / \mathrm{nn} .4202$

12. Tao YX. The melanocortin-4 receptor: physiology, pharmacology, and pathophysiology. Endocr Rev. 2010;31(4):506-543. doi:10.1210/er.2009-0037

13. Huvenne H, Dubern B, Clement K, Poitou C. Rare genetic forms of obesity: clinical approach and current treatments in 2016. Obes Facts. 2016;9(3):158-173. doi:10.1159/000445061

14. Ayers KL, Glicksberg BS, Garfield AS, et al. Melanocortin 4 receptor pathway dysfunction in obesity: patient stratification aimed at MC4R agonist treatment. J Clin Endocrinol Metab. 2018;103(7):2601-2612. doi:10.1210/jc.2018-00258

15. Han JC, Reyes-Capo DP, Liu CY, et al. Comprehensive endocrinemetabolic evaluation of patients with Alström syndrome compared with BMI-matched controls. J Clin Endocrinol Metab. 2018;103 (7):2707-2719. doi:10.1210/jc.2018-00496

16. Farooqi IS, Yeo GS, Keogh JM, et al. Dominant and recessive inheritance of morbid obesity associated with melanocortin 4 receptor deficiency. $J$ Clin Invest. 2000;106(2):271-279. doi:10.1172/JCI9397
17. Martin MG, Lindberg I, Solorzano-Vargas RS, et al. Congenital proprotein convertase $1 / 3$ deficiency causes malabsorptive diarrhea and other endocrinopathies in a pediatric cohort. Gastroenterology. 2013;145(1):138-148. doi:10.1053/j.gastro.2013.03.048

18. Stijnen P, Ramos-Molina B, O'Rahilly S, Creemers JW. PCSK1 mutations and human endocrinopathies: from obesity to gastrointestinal disorders. Endocr Rev. 2016;37(4):347-371. doi:10.1210/er.2015-1117

19. Farooqi IS, Keogh JM, Yeo GS, Lank EJ, Cheetham T, O’Rahilly S. Clinical spectrum of obesity and mutations in the melanocortin 4 receptor gene. N Engl J Med. 2003;348(12):1085-1095. doi:10.1056/ NEJMoa022050

20. Drabkin M, Birk OS, Birk R. Heterozygous versus homozygous phenotype caused by the same MC4R mutation: novel mutation affecting a large consanguineous kindred. BMC Med Genet. 2018;19(1):135. doi:10.1186/s12881-018-0654-1

21. O'Rahilly S, Farooqi IS, Yeo GS, Challis BG. Minireview: human obesity-lessons from monogenic disorders. Endocrinology. 2003;144 (9):3757-3764. doi:10.1210/en.2003-0373

22. Thearle MS, Muller YL, Hanson RL, et al. Greater impact of melanocortin- 4 receptor deficiency on rates of growth and risk of type 2 diabetes during childhood compared with adulthood in Pima Indians. Diabetes. 2012;61(1):250-257. doi:10.2337/db11-0708

23. Ul-Haq Z, Mackay DF, Fenwick E, Pell JP. Meta-analysis of the association between body mass index and health-related quality of life among adults, assessed by the SF-36. Obesity (Silver Spring). 2013;21(3):E322-E327. doi:10.1002/oby.20107

24. Kohlsdorf K, Nunziata A, Funcke JB, et al. Early childhood BMI trajectories in monogenic obesity due to leptin, leptin receptor, and melanocortin 4 receptor deficiency. Int J Obes (Lond). 2018;42 (9):1602-1609. doi:10.1038/s41366-018-0049-6

25. Styne DM, Arslanian SA, Connor EL, et al. Pediatric obesity-assessment, treatment, and prevention: an endocrine society clinical practice guideline. J Clin Endocrinol Metab. 2017;102(3):709-757. doi:10.1210/jc.2016-2573

26. Eneli I, Xu J, Fiedorek F, et al. Tracing the effect of the melanocortin-4 receptor pathway in obesity: study design and methodology of the TEMPO registry. Paper presented at: 57th Annual Meeting of the European Society for Paediatric Endocrinology; September 27-29; 2018; Athens, Greece.

27. Baig S, Paisey R, Dawson C, et al. Defining renal phenotype in Alström syndrome. Nephrol Dial Transplant. Epub October 10, 2018. doi:10.1093/ndt/gfy293
The Application of Clinical Genetics

\section{Publish your work in this journal}

The Application of Clinical Genetics is an international, peerreviewed open access journal that welcomes laboratory and clinical findings in the field of human genetics. Specific topics include: Population genetics; Functional genetics; Natural history of genetic disease; Management of genetic disease; Mechanisms of genetic disease;

\section{Dovepress}

Counselling and ethical issues; Animal models; Pharmacogenetics; Prenatal diagnosis; Dysmorphology. The manuscript management system is completely online and includes a very quick and fair peerreview system, which is all easy to use. Visit http://www.dovepress. com/testimonials.php to read real quotes from published authors. 